\title{
Persona
}

\section{BUSINESS ETHICS: THE SOUNDEST ECONOMIC POLICY FOR ALMOST ALL COMPANIES}

\author{
Entrevista concedida ao CENE - Centro de Estudos de Éțica nas Organizações - pelo Prof. Thomas \\ Donaldson, da Wharton School, University of Pennsylvania, USA, durante sua visita à EAESP/FGV, \\ de 21 a 25 de maio de 1997.
}

CENE: You described Business Ethics as an emerging area of academic teaching and scholarship. Can you tell us some changes in this area occurring in the United States and in Europe?

Prof. Donaldson: Business ethics is a field of inquiry. The field had a tremendous growth in the last 20 years in the United States and Europe. Twenty years ago, when I began speaking and writing in this area, there were only one or two text-books. Today there are 70 or 80 text-books in the US and Europe. Twenty years ago, almost no classes in Business Ethics existed. Today, in the United States you won't find any of the 7,000 universities there that don't in some point or another teach a course in business ethics. Indeed, in the major business schools, ethics is an important part of the curriculum of the school. At Wharton, we require our MBA students to take a module on Business Ethics, and the undergraduate business program, $90 \%$ of the students take a module or a course in business ethics. And we have a new Ph.D. program in the area. Roughly, the same is true at Harvard and at many of the major business schools: Northwestern, The University of Virginia - Darden School. So at short, this field has come from nothing to a rather spectacular array of activities in a short space of two decades. There are now seven academic journals in the area of business ethics. And the evolution was not limited to the United States. In Europe, for example, at the London Business School and INSEAD, active programs in ethics are on their way, with leading European figures in this area.

CENE: All of this energy, all of this activity, what does it mean for business people?

Prof. Donaldson: Let me tell you a little bit some of the exciting things I think we have been learning in the area of research about business ethics. I want to begin with some of the things we learned about the limits of the compliance systems and codes to regulate ethical behaviour in companies. A lot of people, when they think about business ethics, think about codes of ethics, the rules the companies formulate. Here is the striking statistic. The best data we have suggest that at least in the United States, where the survey has been done, there is a slight positive correlation between having a code of ethics and criminal misconduct. That is to say that there is a slight greater inclination to engage in unethical illegal conduct if you have a code of ethics in your corporation than if you don't. That is rather remarkable, isn't it? But you know, it shouldn't be so surprising to us. The research is showing what we know in a deeper level, in a more fundamental level as managers. Ethics has much more to do with leadership and culture than it has to do with the rules that are promulgated in business. A story about an American boy goes like this. 
The boy came home from school and he pulled out of his pocket a magic marker - a marker for his clothes and showed it to his father, who said: you stole, you are a thief, you took the magic marker from the school. You must stay in the house for two months. We have values, we have ethics. And ... if you ever need a marker in the future, let me know, because I can bring one home from the office for you. In many ways this is the lesson that we've been learning about ethics from research and corporate culture. Ethics is like water. It flows from down hill, it flows from the people at the top. And they have no choice in the fact but to lead or mislead.

CENE: You mentioned some dangerous currents in Business Ethics. What do you mean by them?

Prof. Donaldson: They are serious problems that companies have had again and again: teams and performers that are insulated, isolated by themselves, not interacting with others. Examples that are set by other groups that people tend to follow, precedents, blind precedents. Absence of discussion in a language to frame the issues. Uncommon stress, as occurred with Union Carbide in the Bhopal disaster. Goal Mesmerization: people are inclined to target themselves to a goal, not paying attention to anything else, that they lose sight of what is going on.

CENE: You seem to give special attention to the language. Is it true?

Prof. Donaldson: Well, let's see. What is important about having a statement of values in a company? It is not the statement of values, it is not even the code of ethics. I can almost tell you in the United States, if you tell me what the industry is, what the code and the statement of values would look like. They look so much the same that it is not worth paying attention to. What is lots more important is that you have the language and to use the language. Use the language as a leader, use in order to vanquish problems. It is important to talk the language of values or ethics in order to avoid disasters.

CENE: What are the spheres where the ethical values can be recognised?

Prof. Donaldson: If you start thinking, there are three different places that values can occur. They can occur from the individual, each of us brings values into the workplace. They can occur at the organisation level and they can occur in the economic system or the culture. The general rule: the greater the distance and the gap between any of those three spheres, the more likely it is that the company will suffer as a result of a value gap. The stronger the leadership in the centre, the more likely that the values will be maintained.

CENE: Why can't rules maintain values?

Prof. Donaldson: Why can't rules maintain values? People are very clever getting around rules and principles, aren't they? Have you heard the story of the three attorneys, three lawyers? The three lawyers were at the death bed of an old gentleman who made a very strange request. He said: I want each of you to put US\$ 10,000 into may casket. And he handed the US $\$ 10,000$ to each of the attorneys, each of the lawyers. And the lawyers said: Sir, if you don't want, let's do that. Once you are down in the ground, you can't spend the money, you know. We prefer not to ... - No, No! - he said. I gave each one of you the money, I want each one of you to put US\$10,000 in my casket. When he died, and his body was in the casket, each of the lawyers walked by the casket and each of them dropped an envelope into the casket. A little later, they were talking to each other outside the funeral and one of them said. You know, I didn't put all the US\$ 10,000 in the casket. I only put US $\$ 7,500$. You see, I couldn't stand the thought of all that money rying in the ground, that wouldn't help anyone, so I took US $\$ 2,500$ and I gave it to the poor, to the hungry ... and I put
US $\$ 7,500$. The second attorney said: I'm glad you said something, because I didn't put the US\$10,000 in the casket either! I only put US $\$ 5,000$. You see, shortly before our client died, I did a lot of work for him and I never had a chance of sending him a bill, I never had a chance of sending him an invoice. So I took the money that was really mine, and I put the other US $\$ 5,000$ in. The third attorney was shocked. He said: I can't believe you did this to our friend. This was not only our client, he was our personal friend. I did the right thing. I wrote him out a check with the entire amount. The myth is that companies have public relations and ethics disasters because they have a few bad apples, they have a few people who are evil, and cause these things to happen. The truth is, from the research that has been done for the last twenty years, from the examination of many, many cases, all companies have some bad apples. The striking thing about most companies that had serious problems is that the people involved are not evil. They are not saints, and they 


\section{Persona}

are not great sinners, they are somewhere in between. But they usually tend to be in contexts where there are huge pressures on them, predictable contexts. So, much of business ethics - I think - has to do not with helping people find the right thing, and has to do with helping good people who know what the right thing is, avoid to do it wrong and later regret.

CENE: Can a company be profitable and also act ethically?

Prof. Donaldson: Let me speak a little bit about some of the insights we have had about how ethics can play a positive role in achieving traditional performance measures. In other words, in helping with profits. I don't mean to say that a company can't make profits unethically. We know of companies that have done that. But I would assert that over the long term the soundest economic policy for almost all companies is to take values and ethics seriously.

\section{CENE: Why?}

Prof. Donaldson: We've been learning more in the last fifteen years than ever before. Values in companies - we have learned - can help promote efficiency. There are some very interesting academic works showing situations where the interests of the corporation and the interests of the individual employee don't ally. In most situations shared values and sometimes loyalty is the most efficient mechanism for achieving the goals that the company set for itself as traditional. For example, we often teach MBAs in the United States. In effect, to keep your bags packed, as if you were ready to move to another company at any time, don't spend time developing skills that you can't put in the open market. In fact, that turns out to be very inefficient. Some companies require company's specific development skills and to the extent that we can not achieve that we will be less efficient as result.

CENE: Would you correlate Business Ethics to the capitalism?

Prof. Donaldson: The system of the capitalism does not work very efficiently unless it has the ethical cooperation of its participants, at least to a certain extent. Anyone who visited Moscow in the last three or four years notices that the prospects for business right now in the former Soviet Union, or Russia, are not very good. I heard that the amount of external foreign investment in Chile was equal to all the investment that has been made in Russia for the last year. Why isn't the mass of investment going there? In part because the ethical culture that the Russians have almost inherited, looking at their evil capitalist foe, is not a successful recipe for an efficient economy.

CENE: Values help companies to be more efficient?

Prof. Donaldson: Not all values. We have not been able to correlate, for example, giving money away, - which is very good, we should do that - and making more profits. There are stronger correlations to be established between reputation for integrity, specially in key industries, and profits.

CENE: Are there other reasons why values make difference?

Prof. Donaldson: Many companies have found out that they could cut down on bureaucracy by maintaining values. I spoke only three weeks ago to the chairman and top officers at Johnson and Johnson, a US consumer products and pharmaceutical company, and they have been known for a few years as a very strong ethics company and they are also known for being finely decentralised. The buzz world in the United States is empowerment. They empowered groups to create products and to sell them Johnson and Johnson has a strategy that is connected to the values. By getting people to share the values of the Credo, they don't have to have a lot of converse and rules and bureaucracy. They can let individual units in very different industries and areas work on their own while attaining the same level of general reliable quality. Another company that has done that very successfully decentralisation in values is Hewlett Packard. It is hard to imagine Hewlett Packard's success without their emphasis on values.

CENE: You mentioned that ethics is used in a company to motivate people. Wouldn't it mean the instrumentalization of business ethics? Would this be ethical?

Prof. Donaldson: Motivating people. I'm sure you know many directors and managers in Brazil. When they go to the shop floor, or trading floor, or wherever people are doing the real work, have they ever tried this, have they ever said: Come on, people! Let's work hard! Let's maximize return on investment for the shareowner! Do people get excited to hear companies over that kind of talk? Brazil might be very different, but in the United States people kind of go like this... Some of the most successful companies in the world have used values to help motivate people, to make them believe that they are part of a team that is succeeding, and in which they will share some of the rules. We've learned that values help facilitate alliances. In fact, the research that I'm most familiar with shows that the key variable in alliances between companies that are successful is a sharing of values. Work on game theoretic activity shows that to break through prisoners' dilemmas, to share values is probably the most 
important component. One of $\mathrm{my}$ favourite cartoons shows a man coming into a business, into a company. He comes in and he sees a man sitting behind a desk, he sees the sign, and the model for logo and slogan of the company on the sign. It says: We cheat the other guy and pass the savings on to you! We cheat other people and take the saving to give to you. Would you buy a car or a bracelet from this man? I think not because this person has said didn't sell any jeans at all. Some of their Hispanic employees felt that they could and should speak up. They felt in horror. They said: you are crazy! You are idiotic! Our friends look at this Hispanic man going down the alley and they say: what is the matter, doesn't he have any friends? Where is everybody else? Does he want to be all by himself? is that the way he wants to be? Levi Strauss changed the ad, involved other people and almost instantly the product began to sell better. The moral of the story is that in a company where people feel willing to speak up, they can do better in the end, but people won't speak up unless you share certain values.

CENE: We often by his words and slogan that we two do not share fundamental values.

CENE: When you talk about the role of values, you define them as shield. Can you explain that to us?

Prof. Donaldson: Values is a shield. We are learning more and more in this world that we must have the participation of employees and other smart people in the company. Yet, I can tell you. I visited companies that people were so great to speak up that nothing ever gets stung. Levi Strauss is a company in the United States that sells blue jeans. Levi Strauss has celebrated values for years. They have really pushed and emphasized values and ethics. One day, a few years ago, they had advertised for a new kind of jeans. They wanted to appeal to the Hispanic community. They showed a picture of a young man who was very handsome walking by himself down an alley in New York. The background was this granulated Madison Avenue, very fashionable setting and he looked so tough, he looked so good! And they assume that Brazilian companies many times go into crisis because of ethical problems. You mentioned that the values are important to solve problems, mainly when the company is in crisis, but not necessarily in moral crisis. How does that work?

Prof. Donaldson: We should talk about the ability of values that help in crisis. I watched a number of companies that go through crisis and it is not fun. The best company that has ever gone through crisis in the United States was Johnson \& Johnson. I got to know Jim Burke, that at that time was the chairman at Johnson \& Johnson. They had their Tylenol poisoned. Somebody put poison in it. Everybody from the outside said: you have to tell the people that there is nothing wrong, you have to keep selling it, and even with that you are probably not going to succeed. Jim Burke was in the airplane when this broke. He tells me that by the time his plane landed, his people had already made the decision. They went against all the advice. They took the product completely out of the market. People said: you can't do it, because it may have been a Johnson \& Johnson employee. We don't know, because of the poison. He says you have some reasons to suspect that there might be a fault. They pulled the product. Why did they do that? They did it because their Credo, their value statement, said "Our number one concern is with our customer and our customer's welfare." They pulled the product and you probably know the story. They put in place a product that has sold like gamebusters for this decade and probably will do so in the next generation because people trust it. I remind what my friend says: "people and companies are like tea bags, you never know what colour they are until you put them in hot water."

CENE: Well, Prof. Donaldson. We could be talking for hours about so many ethics and values issues that you raised to us, but unfortunately it wouldn't be ethical to do it with you, given your short availability to be among us at this time. We are very grateful for the many interesting ideas on Business Ethics, that you shared with us throughout these days. All of us: teachers, students, partners and other friends who came to hear you are very much impressed with the hard work that has been done in the field of Business Ethics around the world. Your visit to EAESP/FGV has certainly meant an enormous push to the Business Ethics movement in this country. Thanks and ...come back! $\square$

A entrevista foi realizada pela Profa. Maria Cecilia Arruda, coordenadora do CENE - Centro de Estudos de Ética nas Organizações da - EAESP/FGV. e-mail: cene@eaesp.fgvsp.br 